Research Article

\title{
Simulation Study on Strength and Failure Characteristics for Granite with a Set of Cross-Joints of Different Lengths
}

\author{
Dawei Yin, ${ }^{1,2}$ Shaojie Chen $\mathbb{D}^{1,2,3}$ Xingquan Liu, ${ }^{1}$ and Hongfa $\mathrm{Ma}^{1}$ \\ ${ }^{1}$ State Key Laboratory of Mine Disaster Prevention and Control, Shandong University of Science and Technology, \\ Qingdao 266590, China \\ ${ }^{2}$ Key Laboratory of Safety and High-Efficiency Coal Mining, Ministry of Education, Anhui University of Science and Technology, \\ Huainan 232001, China \\ ${ }^{3}$ Centre for Geosciences Computing, School of Earth Sciences, University of Queensland, Brisbane, QLD 4072, Australia
}

Correspondence should be addressed to Shaojie Chen; csjwyb@163.com

Received 16 September 2017; Revised 4 January 2018; Accepted 14 January 2018; Published 13 March 2018

Academic Editor: Rihong Cao

Copyright (c) 2018 Dawei Yin et al. This is an open access article distributed under the Creative Commons Attribution License, which permits unrestricted use, distribution, and reproduction in any medium, provided the original work is properly cited.

The strength and failure characteristics for granite specimen with a set of cross-joints of different lengths were studied using PFC $2 \mathrm{D}$ software. The results show that when the included angle of $\alpha$ between the main joint and loading direction is $30^{\circ}$ or $45^{\circ}$, no matter what the included angle of $\beta$ between main and secondary joints is, the main joint controls crack propagation and failure of granite specimen, which occurs the shear failure propagating from main joint tips, and the corresponding uniaxial compressive strength is low. Meanwhile, the secondary joint is the key joint for crack propagation and failure at $\alpha$ of $0^{\circ}$ and $90^{\circ}$ except when $\beta$ is $90^{\circ}$. The granite specimen occurs the shear failure propagating from secondary joint tips. And, the shear failure crossing upper tips of main and secondary joints is found at $\alpha$ of $0^{\circ}$ or $90^{\circ}$ and $\beta$ of $90^{\circ}$. Their uniaxial compressive strengths are large. Also, the combined actions of main and secondary joints determine crack propagation and failure at $\alpha$ of $60^{\circ}$ except when $\beta$ is $90^{\circ}$. The granite specimen occurs the hybrid failure, including shear failure propagating from main joint tips and tensile failure propagating from main and secondary joints center or secondary joint tips. And, when $\alpha$ is $60^{\circ}$ and $\beta$ is $90^{\circ}$, the granite specimen occurs the shear failure along secondary joint plane direction, and its uniaxial compressive strength is small. Generally, when $\alpha$ or $\beta$ is a fixed value, the uniaxial compressive strength firstly decreases and then increases with the increase of $\beta$ or $\alpha$. Additionally, when $\alpha$ is $60^{\circ}$ and $\beta>45^{\circ}$, the uniaxial compressive strength represents a decreasing trend. The uniaxial compressive strength at $\alpha$ and $\beta$ between $30^{\circ}$ and $60^{\circ}$ is generally small. Finally, the microdisplacement field distributions of granite specimen were discussed.

\section{Introduction}

Under the effects of geological tectonic stress field, there are a significant amount of native defects in a natural rock mass, such as joints, fractures, faults, various microinclusions, and pores. These native defects play an important role in the mechanical properties of the rock mass, further influencing the stability of underground engineering [1-3]. Among them, the joint is a common native defect. It is significant to study the strength and failure characteristics of jointed rock mass.

Many experimental and numerical simulation studies have been conducted on the strength and failure characteristics of natural jointed rock masses by many scholars, and they have obtained many interesting results. $\mathrm{Li}$ et al. performed the conventional triaxial compression tests on the marble specimens containing natural joints, and the effects of joint angle (between the joint plane and major principal stress) varying from $29.3^{\circ}$ to $56.0^{\circ}$ on the strength and failure model were studied [4]. Through conventional triaxial compression tests on the shale, three failure modes were found by Niandou et al., which was affected by the included angle between joint plane and major principal stress, and confining pressure [5]. Mao and Yang have carried out the uniaxial and triaxial compression tests of slate with single set of structural planes, and they established one-dimensional and three-dimensional 
intensity variation law of slate with single set of structural planes using single discontinuities theory [6]. Prudencio and Jan performed the biaxial compression tests on the physical models of rock with nonpersistent joints, and the effects of joint spacing, joint angle, and joint arrangement on the characteristics of failure mode, strength, and deformation of rock mass were studied [7]. By conducting the uniaxial compression tests on gypsum specimens with a set of preexisting open flaws, the influences of joint inclination angle and joint connectivity rate on uniaxial compression strength, elastic modulus, and stress-strain curves of rock mass were well investigated by Chen et al. [8]. Using a new shear device, Gehle and Kutter studied the breakage and shear behavior of intermittent rock joints [9]. Xiao et al. studied the deformation and strength of columnar jointed rock-like material made of the mixtures of plaster, cement, and water under uniaxial compression and proposed four types of failure modes of columnar jointed rock mass under uniaxial compression [10]. Goldstein et al. studied the size effects on the strength of jointed rock mass under uniaxial compression [11]. The true-triaxial compression tests focused on the influences of orientation and the intermediate principal stress of joints on the rock mass strength were carried out by Reik and Zacas [12]. Laijtai performed the direct shear test on the intermittent jointed rock mass, and the composite damage theory was put forward [13]. Based on the equivalent rock mass (ERM) technique, Zhou et al. performed the triaxial compression simulation on the jointed rock mass using the $\mathrm{PFC}^{3 \mathrm{D}}$ software [14]. And, they found that the deformation and failure behavior were affected by joint degradation, the microcrack formation in the intact rock, the interaction between two joints, and the interactions of microcracks and joints. Using FLAC software, the effects of joint angle on the peak strength, mechanical behavior, and pattern of shearband (SB) of the anisotropic jointed rock specimen [15] were studied. Using $\mathrm{PFC}^{2 \mathrm{D}}$ software, Yang and Huang carried out the Brazilian splitting test for the jointed rock specimen, and the effects of joint angle and notch angle on the tensile strength and failure mode of jointed rock specimens were detailed analyzed [16]. Yang et al. studied the growth mechanism of three-dimensional (3D) cracks in rocks under tension as well as the strength and failure behavior of samples [17]. Morgan et al. studied the cracking processes in Barre granite, including the fracture process zones and crack coalescence [18]. Also, the effects of joint angle in coal on the failure mechanical behavior of a roof rock-coal combined body were studied by Yin et al. [19].

The aforementioned achievements have great important significances for understanding the strength and failure characteristics of jointed rock mass. However, most of the above studies are focused on the rock mass containing single joint, groups of parallel joints, or nonpersistent joints. And, in the actual rock mass engineering, the joints generally occur in the form of a cross. Due to the difficulty in sampling for the rock specimen with cross-joints, there are few studies on the strength and failure characteristics of rock mass with cross-joints. The strength and failure characteristics of the rock specimen containing two sets of cross-joints with equal lengths were studied by Kulatilake et al. [20] and Huang and Yang [21]. At the same time, the cross-joints in rock mass may be of different lengths.

For these, in this paper, the uniaxial compression tests for granite specimens containing a set of cross-joints with different lengths were simulated by $\mathrm{PFC}^{2 \mathrm{D}}$ software. And, on the basic of variations of the included angles of $\alpha$ between the main joint and loading direction, and $\beta$ between the main joint and secondary joint, the effects of cross-joints on strength and failure characteristics were analyzed. The above achievements are of great significances for understanding mechanical properties of jointed rock mass.

\section{Uniaxial Compression Model for Granite Specimen Containing a Set of Cross-Joints with Different Lengths}

2.1. Particle Flow Code. The particle flow code (PFC) is an effective method to study the macromechanics problems of an analytic object (including construction and rock mass) at the microlevel [22-26], which has been widely applied in simulation tests of uniaxial compression, biaxial compression, and triaxial compression for the rock specimen $[19,27-30]$. There are two bonding models in PFC $2 \mathrm{D}$ software, including the contact bond model and parallel bond model [26-30]. Among them, the parallel bond can transmit both force and moment between particles, which is well applied to simulate the compact material, such as rock material. In this study, we built the uniaxial compression model for the granite specimen containing a set of crossjoints with different lengths using the parallel bond.

2.2. Microparameters of Granite Specimen. In the parallel bond model, the macromechanical properties of the simulation model are mainly determined by microparameters of particles, such as the contact modulus of particles, particle stiffness ratio, elastic modulus of parallel bonding particles, normal strength of parallel bonding particles, shear strength of parallel bonding particles, and ratio of parallel bonding normal stiffness to parallel bonding shear stiffness. However, these microparameters cannot be directly achieved by the laboratory tests. Therefore, before running the uniaxial compression tests, a lot of numerical simulation tests under same conditions as laboratory tests should be conducted until that it can well reproduce the macromechanical properties measured in the laboratory test. And, the determinations of microparameters are a process of minimizing the errors between the numerical results and experimental results.

Due to the limitation of laboratory test condition, the microparameters of granite provided by Zhang et al. [31, 32] were used to carry out numerical test. Firstly, Zhang et al. conducted the triaxial compression tests for the standard granite specimen [31]. And, the mechanical parameters (shown in Table 1) of triaxial compression of the standard granite specimen were selected as the reference basis for determining the microparameters. Then through the method of "trial and error" repeated check comparison, the microparameters of granite were well achieved, as shown in Table 2. 
TABle 1: Physicomechanical parameters and PFC results.

\begin{tabular}{lccc}
\hline Macromechanical parameter & $\begin{array}{c}\text { Triaxial compression test } \\
\text { result }\end{array}$ & $\begin{array}{c}\text { Numerical simulation } \\
\text { result }\end{array}$ & $\begin{array}{c}\text { Error between triaxial compression test } \\
\text { result and numerical simulation result }\end{array}$ \\
\hline Elastic modulus $(\mathrm{GPa})$ & 28.7 & 28.4 & $1.05 \%$ \\
Triaxial compressive strength under & 130.5 & 132.8 & $1.76 \%$ \\
confining pressure of 6 MPa (MPa) & 0.2300 & 0.2285 & $0.65 \%$ \\
Poisson's ratio & 15.9 & 20.87 & $31.26 \%$ \\
Cohesive force $(\mathrm{MPa})$ & 49.86 & 43.68 & $12.39 \%$ \\
Internal friction angle $\left({ }^{\circ}\right)$ & & & \\
\hline
\end{tabular}

TABle 2: Microparameters of granite.

\begin{tabular}{|c|c|c|c|}
\hline Microparameter & Value & Microparameter & Value \\
\hline Minimum particle size $(\mathrm{mm})$ & 0.3 & Elastic modulus of parallel bonding particles $(\mathrm{GPa})$ & 43 \\
\hline Particle size ratio & 1.66 & Normal strength of parallel bonding particles $(\mathrm{MPa})$ & $88 \pm 10$ \\
\hline Density $\left(\mathrm{kg} / \mathrm{m}^{3}\right)$ & 2800 & Shear strength of parallel bonding particles $(\mathrm{MPa})$ & $160 \pm 10$ \\
\hline Contact modulus of particles (GPa) & 5 & $\begin{array}{c}\text { Parallel bonding normal stiffness/parallel bonding } \\
\text { shear stiffness }\end{array}$ & 3 \\
\hline $\begin{array}{l}\text { Contact normal stiffness/contact shear stiffness } \\
\text { Coefficient of friction }\end{array}$ & 3 & $\begin{array}{l}\text { Parallel bond radius multiplier } \\
\qquad 0.8\end{array}$ & 1 \\
\hline
\end{tabular}

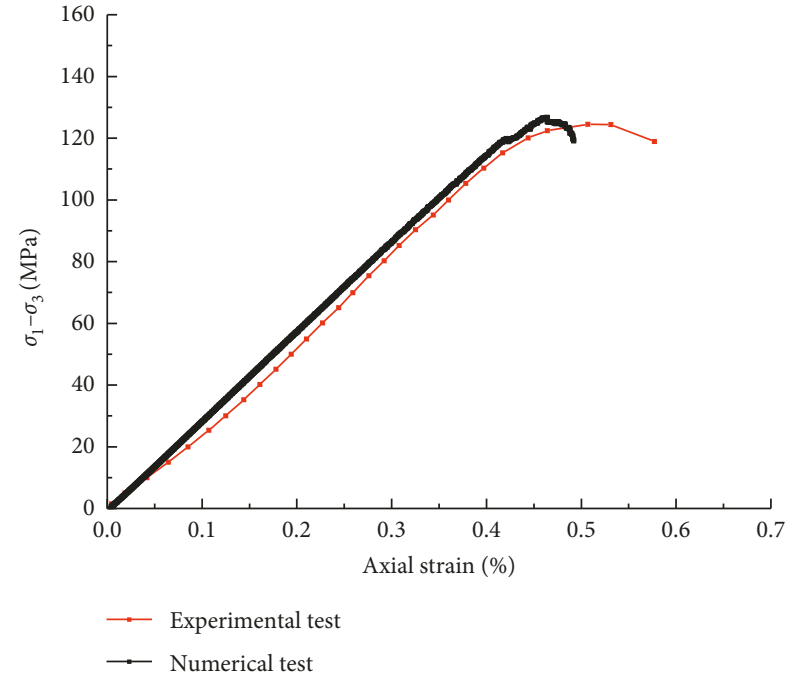

Figure 1: Comparison of stress-strain curves obtained by experiment and simulation under triaxial test.

At the same time, the difference between the test values of cohesive force and internal friction angle is larger than that of the simulated values. This is the result of circular particles used in the simulation model [32]. Figures 1 and 2 show the comparison of stress-strain curves and failure modes obtained by experiment and simulation under triaxial test of confining pressure of $6 \mathrm{MPa}$, respectively. In Figures 1 and 2, the simulated stress-strain curve and failure mode are in good agreement with the laboratory test of the real granite specimen.

\subsection{Model Construction for Granite Specimen Containing a Set} of Cross-Joints with Different Lengths. A particle flow model of the granite specimen with a set of cross-joints with different lengths was established by radius extension, as shown in Figure 3. The model size is $70 \mathrm{~mm} \times 140 \mathrm{~mm}$. And, a total of 16459 particle samples were generated in the model. The

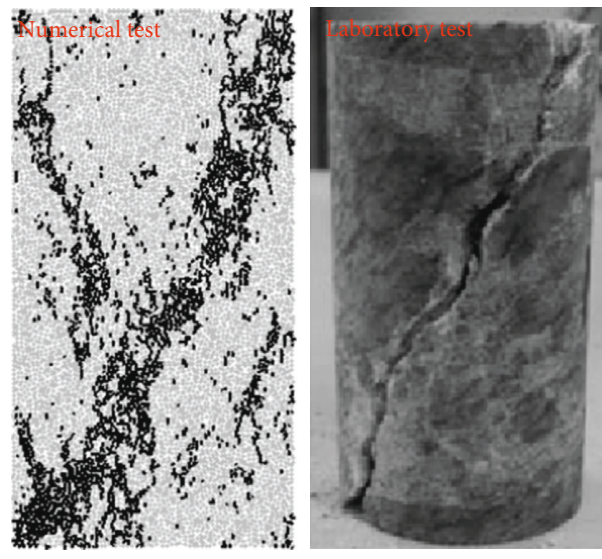

FIgURE 2: Comparison of failure modes obtained by experiment and simulation under triaxial test.

minimum particle radius is $0.3 \mathrm{~mm}$, and the ratio of largest to smallest radius of particle is chosen as 1.66. A set of crossjoints with different lengths were created through JSET command. For distinguishing the main joint and secondary joint, particles passing through the main joint plane are represented by red, while particles passing through the secondary joint plane are represented by blue. And, centers of the main joint, secondary joint, and granite specimen are coincident. The lengths of the main joint and secondary joint are $30 \mathrm{~mm}$ and $20 \mathrm{~mm}$, respectively. Additionally, the included angle between the main joint and loading direction is $\alpha$, and $\beta$ is the included angle between the main joint and secondary joint.

A joint plane contact is defined in $\mathrm{PFC}^{2 \mathrm{D}}$ software as a special contact that exists between particles that fall on opposite sides of the joint plane [33]. According to the previous studies, the microparameters of the joint plane were weakened and generally set as very small values $[19,26-29]$. In this study, the microparameters of the main 


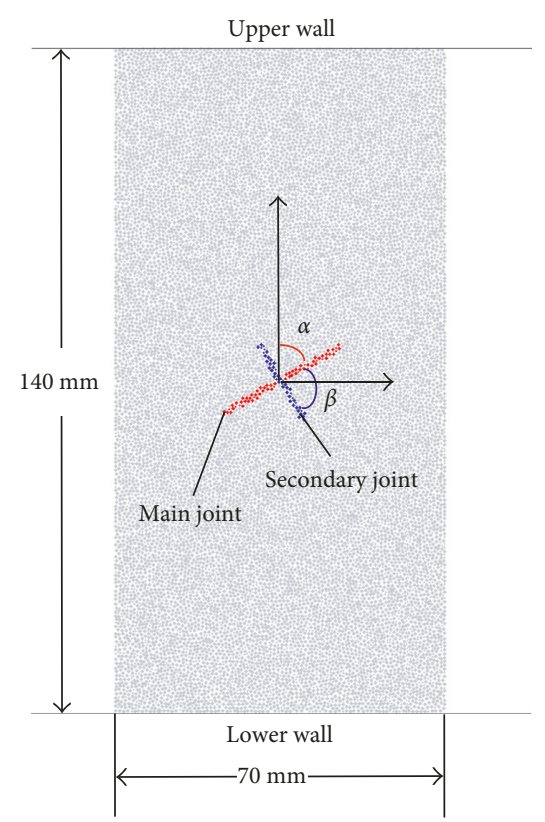

FIGURE 3: Simulation model for the granite specimen with a set of cross-joints with different lengths.

joint plane were taken the same as that of the secondary joint plane. Among them, the friction coefficient was set as 0.1, and parallel bond normal strength and parallel bond tangential strength were all set as 0 .

Now, the uniaxial compression model for the granite specimen with a set of cross-joints with different lengths was built. For this work to be executed, the loading was performed by moving the upper and lower walls at a loading rate of $0.1 \mathrm{~m} / \mathrm{s}$. In PFC $2 \mathrm{D}$ software, the time step is about $4.2 \times 10^{-8} \mathrm{~s} / \mathrm{step}$. Thus, $0.1 \mathrm{~m} / \mathrm{s}$ can be converted into $4.2 \times 10^{-9} \mathrm{~m} / \mathrm{step}$. That is, the upper and lower walls moving $1 \mathrm{~mm}$ require about 238095 steps. Also, the loading rate of $0.2 \mathrm{~m} / \mathrm{s}$ is sufficient to ensure that the rock samples are under quasistatic loading [34]. Therefore, in this study, the loading rate of $0.1 \mathrm{~m} / \mathrm{s}$ can ensure that uniaxial compression models are under quasistatic loading.

2.4. Simulation Test Conditions. In this study, $\alpha$ and $\beta$ were all taken as $0^{\circ}, 30^{\circ}, 45^{\circ}, 60^{\circ}$, and $90^{\circ}$, respectively. Then, $\alpha$ and $\beta$ were combined with each other, and there are 25 test simulation conditions, as shown in Table 3 . The simulation test conditions of $1,6,11,16$, and 21 are single jointed granite specimens.

\section{Strength Characteristics}

3.1. Effects of $\alpha$ and $\beta$ on the Stress-Strain Behavior. Figure 4 illustrates the stress-strain curves of granite specimens under a definite value of $\alpha$. And, Table 4 gives the simulation results, including the uniaxial compressive strength and elastic modulus.

In Figure 4, the stress-strain curves of granite specimens under different simulation test conditions are basically
TABLE 3: Simulation test conditions.

\begin{tabular}{lccccc}
\hline Condition & $\alpha\left(^{\circ}\right)$ & $\beta\left(^{\circ}\right)$ & Condition & $\alpha\left(^{\circ}\right)$ & $\beta\left(^{\circ}\right)$ \\
\hline 1 & & 0 & 14 & 45 & 60 \\
2 & & 30 & 15 & & 90 \\
3 & 0 & 45 & 16 & & 0 \\
4 & & 60 & 17 & & 30 \\
5 & & 90 & 18 & 60 & 45 \\
6 & & 0 & 19 & & 60 \\
7 & & 30 & 20 & & 90 \\
8 & 30 & 45 & 21 & & 0 \\
9 & & 60 & 22 & & 30 \\
10 & & 90 & 23 & 90 & 45 \\
11 & & 0 & 24 & & 60 \\
12 & 45 & 30 & 25 & & 90 \\
13 & & 45 & & - & \\
\hline
\end{tabular}

consistent, which can be divided into three stages, ranging from linear elastic deformation stage, nonlinear deformation stage, to postpeak strain softening stage. And, the included angles of $\alpha$ and $\beta$ affect the uniaxial compressive strength and axial strain values required for each stage. At the same time, the elastic modulus almost does not change with the included angles of $\alpha$ and $\beta$, indicating that the stress-stain curves are coincident in the linear elastic deformation stage. And, these are verified in Table 4. In Table 4, the elastic modulus of granite specimens is basically similar. This is principally because that there is no initial compression stage in $\mathrm{PFC}^{2 \mathrm{D}}$ software, which is different form the physical test [35]. And, this phenomenon can be found in many simulation studies using $\mathrm{PFC}^{2 \mathrm{D}}$ software [19, 26-29].

3.2. Effects of $\alpha$ and $\beta$ on the Strength Characteristics. Figure 5 shows the variation regularities of the uniaxial compressive strength with $\alpha$ and $\beta$, respectively.

In Figure 5(a), when $\beta$ is a fixed value, the uniaxial compressive strength decreases in the first place and then increases with the increase of $\alpha$. When $\beta$ is $0^{\circ}$, the granite specimens are the single jointed specimens. The variation regularity of uniaxial compressive strength with $\alpha$ is consistent with that of the single jointed rock specimen, verifying the accuracies of the simulation. However, when $\beta$ is $45^{\circ}$ or $60^{\circ}$, the uniaxial compressive strength shows a decreasing trend at $\alpha$ of $90^{\circ}$ compared with that at $\alpha$ of $60^{\circ}$. Through previous studies and macrofailure patterns of granite specimens (shown in Figure 6), the uniaxial compressive strength corresponding to the shear failure along the joint plane direction is relatively low. The granite specimen at $\alpha$ of $90^{\circ}$ and $\beta$ of $45^{\circ}$ is mainly destroyed by the shear failure basically along the secondary joint plane direction. The hybrid failures occur in the granite specimen at $\alpha$ of $90^{\circ}$ and $\beta$ of $60^{\circ}$, including the shear failure basically along the secondary joint plane direction and tensile failure propagating from the lower tip of the secondary joint. Thus, their uniaxial compressive strengths decrease at a certain extent.

In Figure 5(b), the uniaxial compressive strength firstly decreases and then increases with the increase of $\beta$ under a fixed value of $\alpha$. At the same time, when $\alpha$ is $60^{\circ}$ and $\beta>45^{\circ}$, the uniaxial compressive strength represents a decreasing 


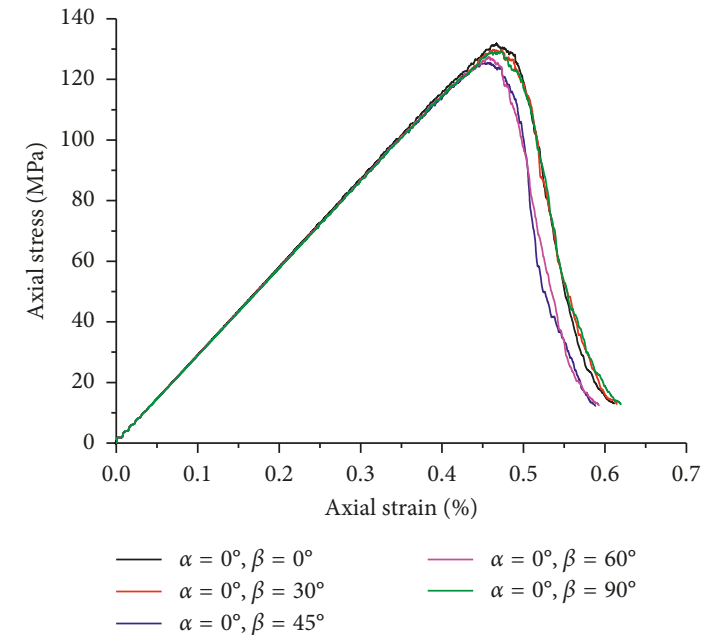

(a)

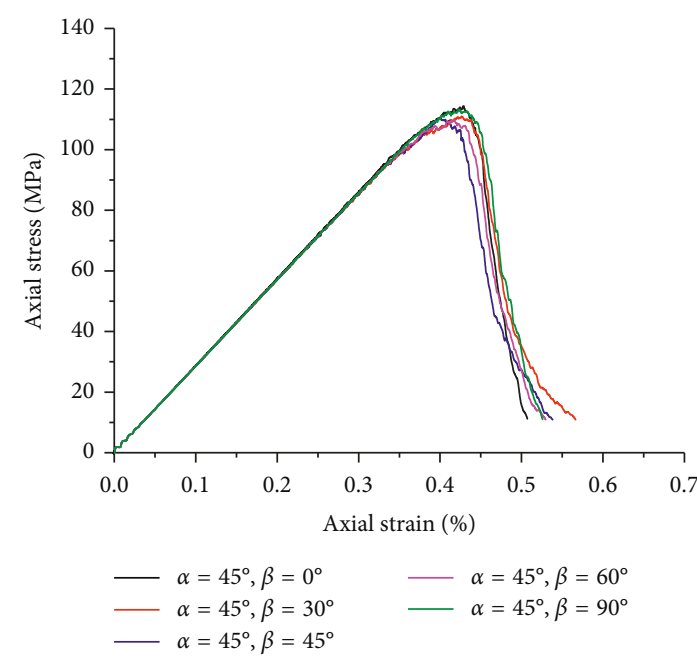

(c)

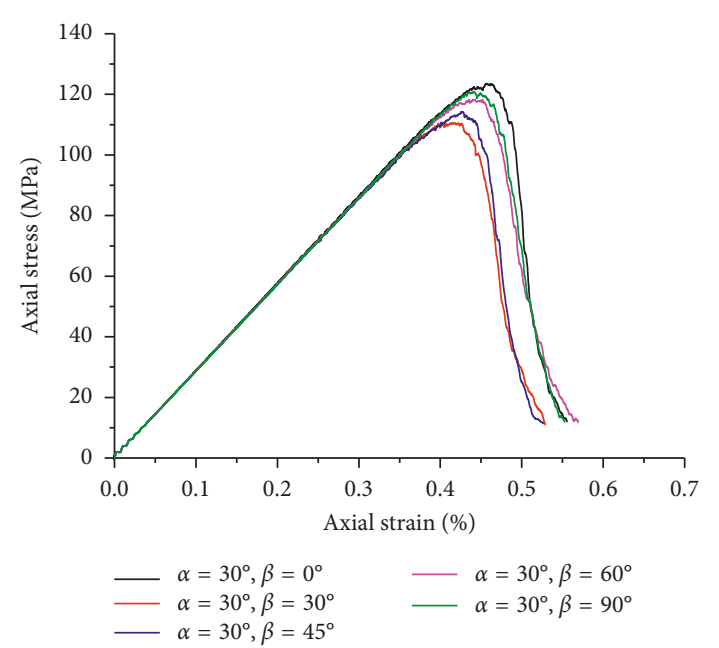

(b)

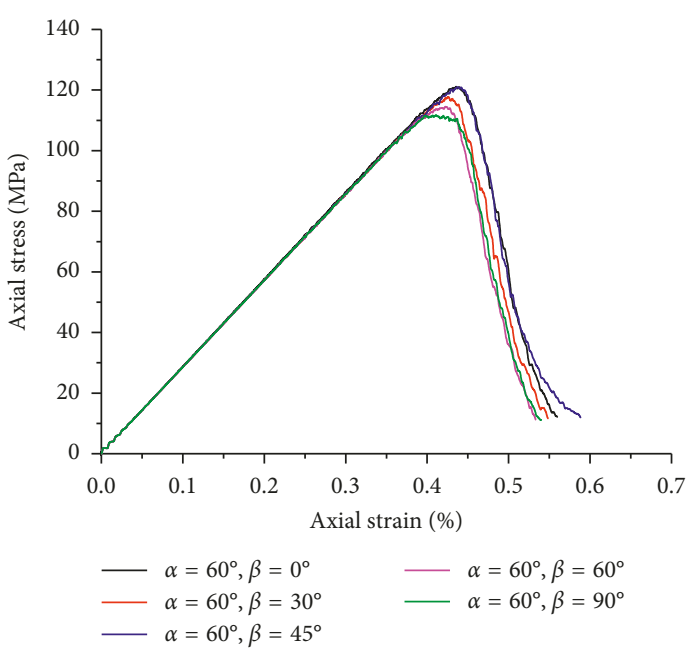

(d)

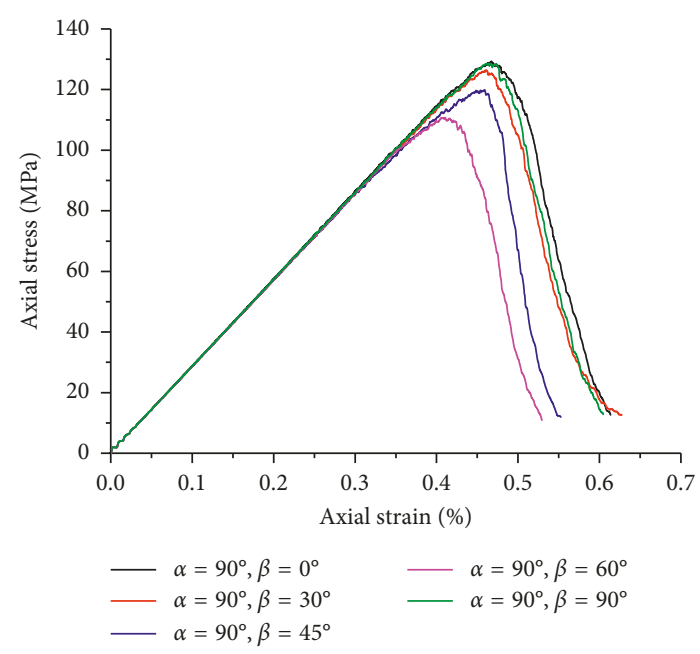

(e)

FiguRE 4: Stress-strain curves of the granite specimens under a definite value of $\alpha$. (a) $\alpha=0^{\circ}$, (b) $\alpha=30^{\circ}$, (c) $\alpha=45^{\circ}$, (d) $\alpha=60^{\circ}$, and (e) $\alpha=90^{\circ}$.

trend. Among them, the shear failure along the secondary joint plane direction causes the failure of the granite specimen at $\beta$ of $90^{\circ}$. Thus, the corresponding uniaxial compressive strength is relatively small. And, the failure patterns at $\beta$ of $45^{\circ}$ and $60^{\circ}$ are basically similar and hybrid failure model, including the shear failure propagating from 
TABLE 4: Simulation test results.

\begin{tabular}{lccccc}
\hline Condition & $\begin{array}{c}\text { Uniaxial compressive strength } \\
(\mathrm{MPa})\end{array}$ & $\begin{array}{c}\text { Elastic modulus } \\
(\mathrm{GPa})\end{array}$ & $\begin{array}{c}\text { Condition } \\
\text { Uniaxial compressive strength } \\
(\mathrm{MPa})\end{array}$ & $\begin{array}{c}\text { Elastic modulus } \\
(\mathrm{GPa})\end{array}$ \\
\hline 1 & 131.97 & 29.10 & 14 & 109.85 & 28.57 \\
2 & 129.89 & 28.88 & 15 & 113.42 & 28.58 \\
3 & 125.59 & 28.87 & 16 & 121.19 & 28.82 \\
4 & 127.47 & 28.86 & 17 & 121.82 & 28.64 \\
5 & 129.41 & 28.88 & 18 & 114.58 & 28.65 \\
6 & 123.55 & 28.93 & 19 & 111.85 & 28.61 \\
7 & 110.68 & 28.71 & 20 & 129.3 & 28.66 \\
8 & 114.28 & 28.60 & 21 & 126.38 & 28.84 \\
9 & 118.34 & 28.65 & 22 & 119.89 & 28.54 \\
10 & 120.87 & 28.71 & 23 & 110.78 & 28.54 \\
11 & 114.48 & 28.79 & 24 & 128.64 & 28.61 \\
12 & 111.06 & 28.53 & 25 & & - \\
13 & 110.33 & 28.54 & & & 28.78 \\
\hline
\end{tabular}

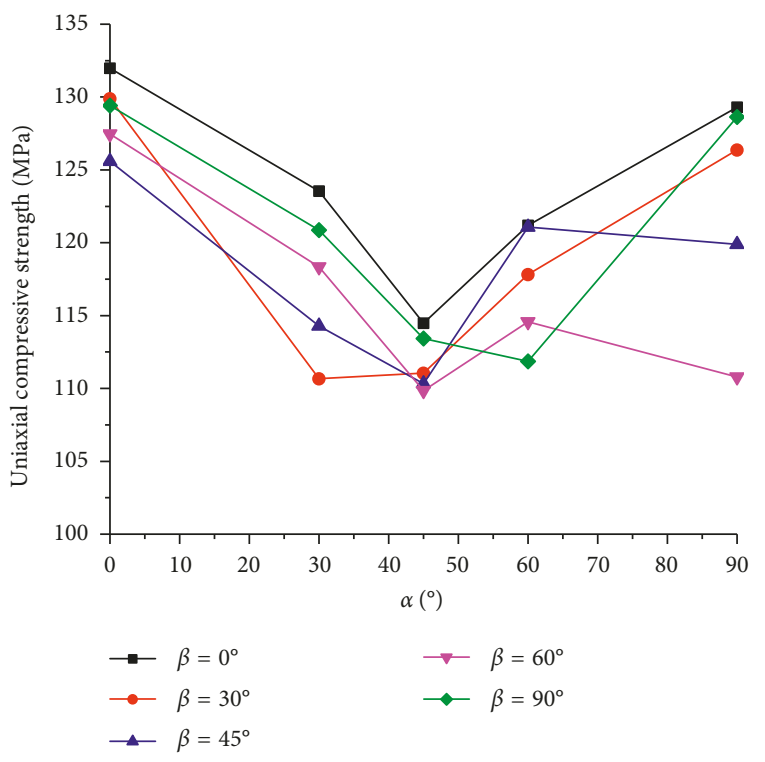

(a)

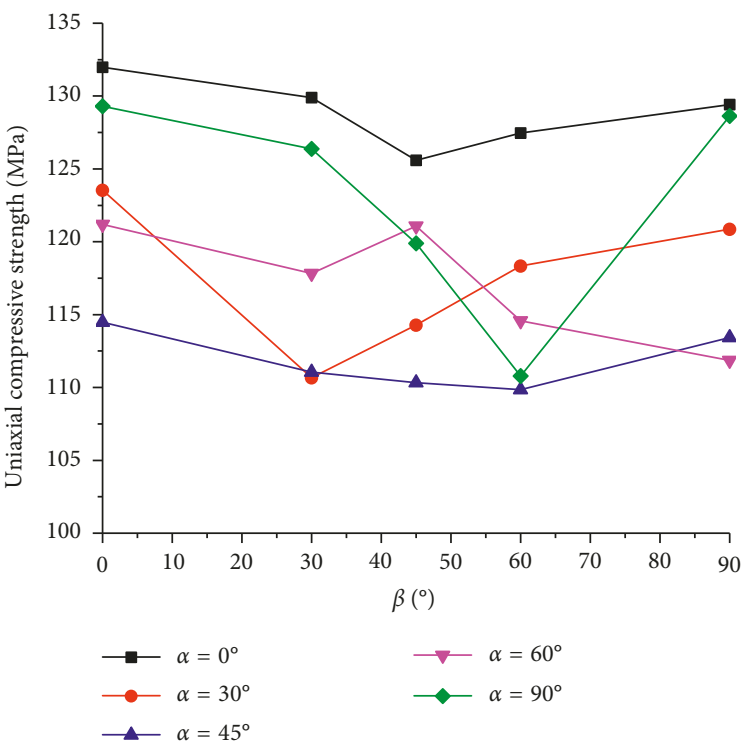

(b)

Figure 5: Relationships between (a) uniaxial compressive strength and $\alpha$ and (b) uniaxial compressive strength and $\beta$.

main joint tips and tensile failure propagating from the joint center or the secondary joint tips. Their shear crack propagation paths are similar. At the same time, tensile crack propagation paths are not the same, especially the crack 1 and crack 2 as shown in Figure 6. In $\mathrm{PFC}^{2 \mathrm{D}}$ software, only when the stress intensity transmitted between the particles is larger than the parallel bonding forces between the particles, the microcrack can be generated. Propagation path of crack 1 is larger than crack 2, which means more external forces are needed to the overcome parallel bonding forces for microcracks formation. Correspondingly, the uniaxial compressive strength is larger. Thus, the uniaxial compressive strength at $\beta$ of $45^{\circ}$ is larger than that at $\beta$ of $60^{\circ}$.

The influences of $\alpha$ and $\beta$ on the uniaxial compressive strength are summarized in Figure 7. Generally, when $\alpha$ and $\beta$ are all between $30^{\circ}$ and $60^{\circ}$, the uniaxial compressive strength of the granite specimen is generally small.

\section{Failure Characteristic Analysis}

4.1. Macrofailure Patterns of Granite Specimen. Figure 6 gives the macrofailure patterns under different simulation test conditions. The failure characteristics of granite specimens were concretely analyzed as follows.

4.1.1. $\alpha$ of $0^{\circ}$ or $90^{\circ}$. When $\beta$ is $0^{\circ}$, the main joint and secondary joint are coincident. Now the granite specimens are single jointed specimens. And, their failures are the hybrid failure pattern, including the shear failure and splitting failure. When $\beta$ ranges from $30^{\circ}$ to $60^{\circ}$, the secondary joint is the key joint for crack propagation and failure of the granite specimen. The granite specimens are mainly destroyed by the shear failure propagating from the secondary joint tips. And, the secondary failure cracks propagating from the main joint tips occur in different degrees. However, when $\alpha$ is $90^{\circ}$ 


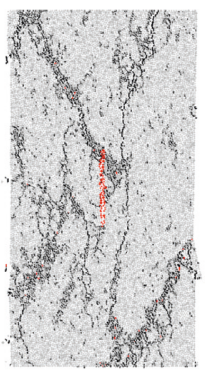

$\alpha=0^{\circ}, \beta=0^{\circ}$

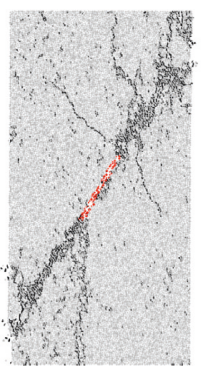

$\alpha=30^{\circ}, \beta=0^{\circ}$

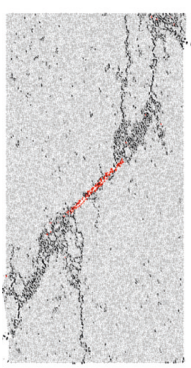

$\alpha=45^{\circ}, \beta=0^{\circ}$

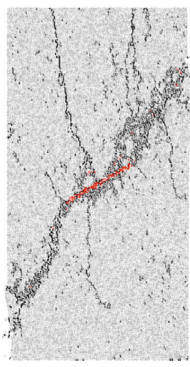

$\alpha=60^{\circ}, \beta=0^{\circ}$

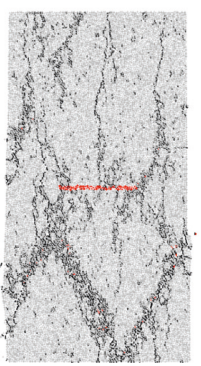

$\alpha=90^{\circ}, \beta=0^{\circ}$

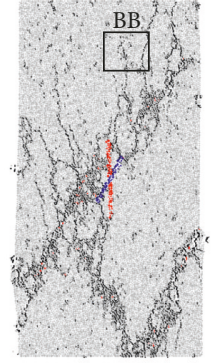

$\alpha=0^{\circ}, \beta=30^{\circ}$

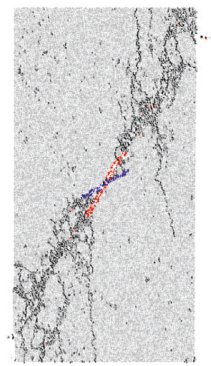

$\alpha=30^{\circ}, \beta=30^{\circ}$
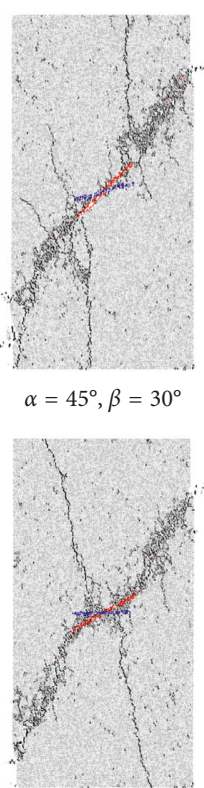

$\alpha=60^{\circ}, \beta=30^{\circ}$

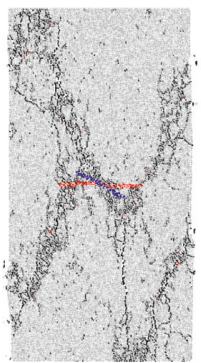

$\alpha=90^{\circ}, \beta=30^{\circ}$

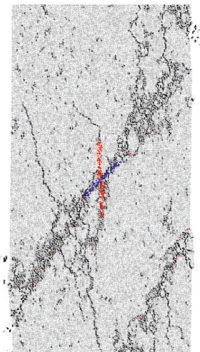

$\alpha=0^{\circ}, \beta=45^{\circ}$

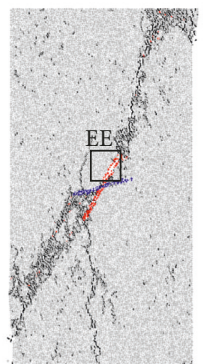

$\alpha=30^{\circ}, \beta=45^{\circ}$

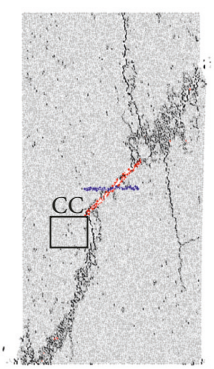

$\alpha=45^{\circ}, \beta=45^{\circ}$

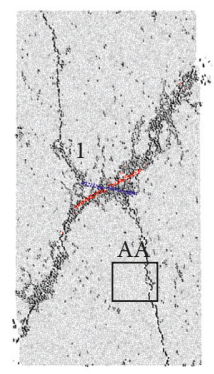

$\alpha=60^{\circ}, \beta=45^{\circ}$

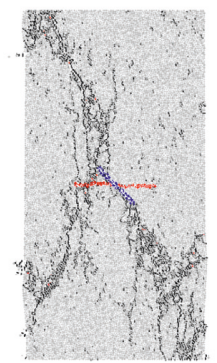

$\alpha=90^{\circ}, \beta=45^{\circ}$
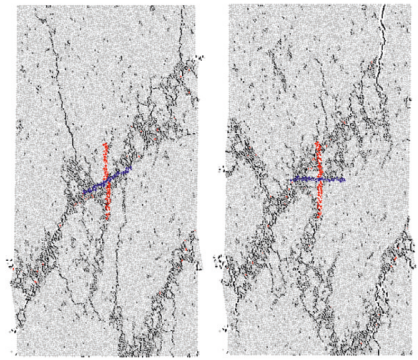

$\alpha=0^{\circ}, \beta=60^{\circ}$

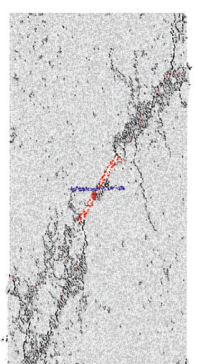

$\alpha=30^{\circ}, \beta=60^{\circ}$

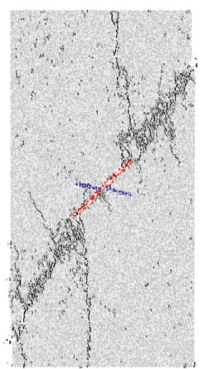

$\alpha=45^{\circ}, \beta=60^{\circ}$

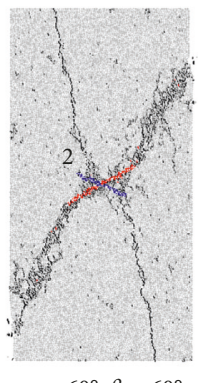

$\alpha=60^{\circ}, \beta=60^{\circ}$

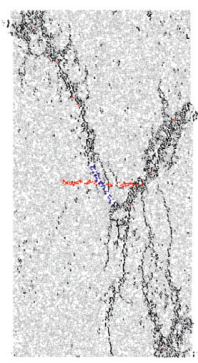

$\alpha=90^{\circ}, \beta=60^{\circ}$

$$
\alpha=0^{\circ}, \beta=90^{\circ}
$$

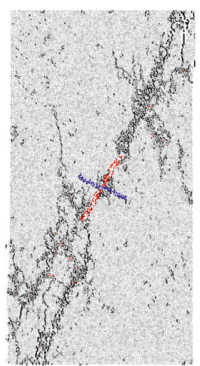

$\alpha=30^{\circ}, \beta=90^{\circ}$

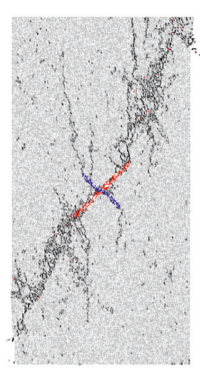

$\alpha=45^{\circ}, \beta=90^{\circ}$
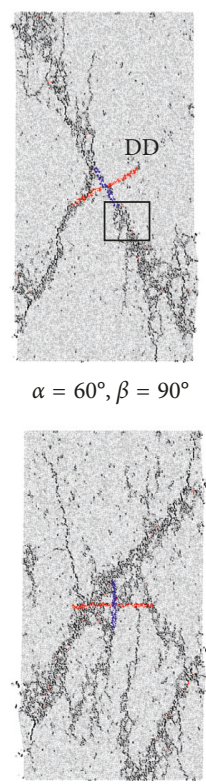

$\alpha=90^{\circ}, \beta=90^{\circ}$

FIGURE 6: Failure patterns of granites containing a set of cross-joints with different lengths.

and $\beta$ is $30^{\circ}$, the failure of the granite specimen is caused by the combined actions of the shear failures propagating from the main joint tips and upper tip of the secondary joint and the tensile failure propagating from the lower tip of the secondary joint. Additionally, when $\alpha$ is $0^{\circ}$ or $90^{\circ}$ and $\beta$ is $90^{\circ}$, the failure of the granite specimen is the shear failure crossing upper tips of the main and secondary joints, accompanied by shear failures at the bottom. 


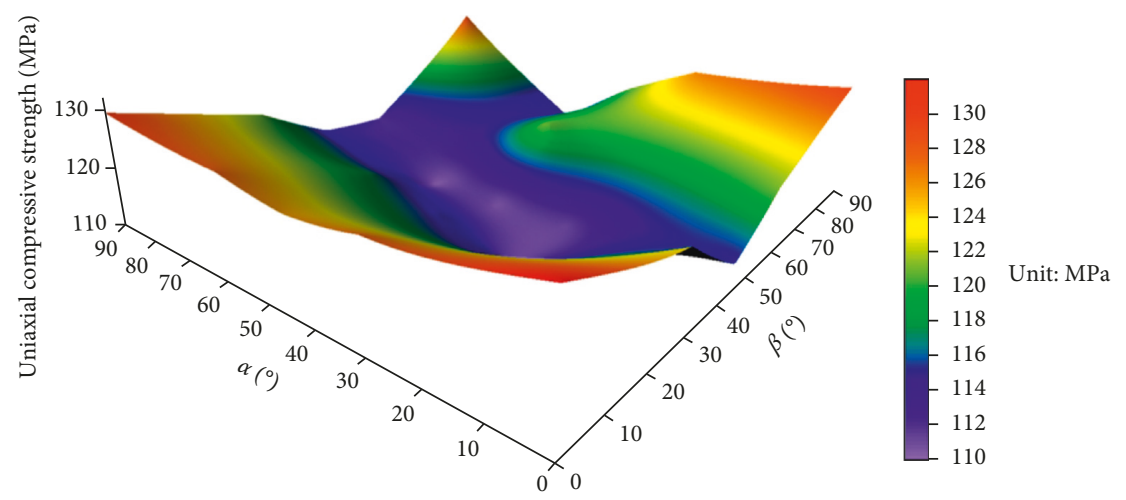

FIgURE 7: 3D graph of uniaxial compressive strengths of granite specimens containing a set of cross-joints with different lengths.

4.1.2. $\alpha$ of $30^{\circ}$ or $45^{\circ}$. No matter what the value of $\beta$ is, the shear failure propagating from the main joint tips causes the failure of the granite specimen, illustrating that the main joint is the key joint for crack propagation and failure of the granite specimen.

4.1.3. $\alpha$ of $60^{\circ}$. When $\beta$ is $0^{\circ}$, the shear failure propagating from single joint tips is the main failure of the granite specimen, accompanied by tensile failure propagating from the joint center. And, when $\beta$ are $30^{\circ}, 45^{\circ}$, and $60^{\circ}$, the failures of granite specimens are the hybrid failure patterns, including the shear failure propagating from the main joint tips and tensile failure propagating from the joint center or secondary joint tips. And, the tensile failure degree is larger than that at $\beta$ of $0^{\circ}$, illustrating that the secondary joint enhances the tensile failure. Additionally, the secondary joint is the key joint for crack propagation and failure of the granite specimen at $\beta$ of $90^{\circ}$. The granite specimen occurs shear failure along the secondary joint plane direction.

4.2. Microdisplacement Field Distributions of Granite Specimen. The microdisplacement distribution is helpful to reveal micromechanism of crack propagation $[15,18]$. Figure 8 presents the microdisplacement distributions of the macrotensile crack and macroshear crack. And, the icons of $\mathrm{AA}, \mathrm{BB}, \mathrm{CC}, \mathrm{DD}$, and $\mathrm{EE}$ correspond to $\mathrm{AA}, \mathrm{BB}, \mathrm{CC}, \mathrm{DD}$, and $\mathrm{EE}$ in Figure 6.

In Figure 8, there are three types of mesodisplacement field distributions for macrotensile crack. Firstly, the particles move in the same direction, and then parts of them change the movement direction (shown in Figure 8(a) AA), or they move apart (shown in Figure 8(a) BB). Thus, the microcracks are generated. And, these two kinds of mesodisplacement field distributions for macrotensile crack are basically consistent with research results studied by Zhang and Wong [36]. The third one is that particles move in opposite directions for microcrack generation, as shown in Figure 8(a) CC. Moreover, particles located on both sides of macroshear crack move in the parallel and opposite directions.

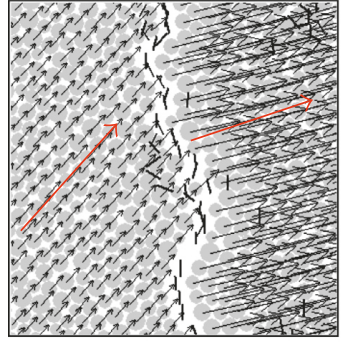

AA

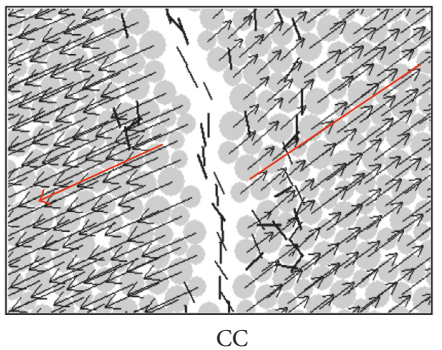

(a)
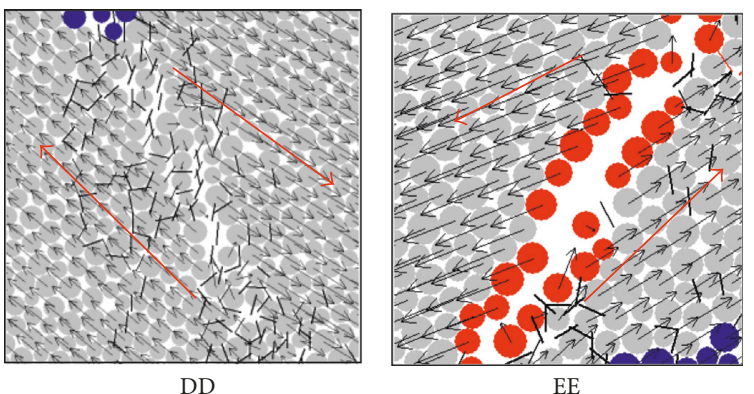

(b)

FIgURE 8: Mesodisplacement field distribution of (a) macrotensile crack and (b) macroshear crack.

\section{Conclusions}

According to the above analysis, the following conclusions were drawn:

(1) The included angles of $\alpha$ and $\beta$ affect the uniaxial compressive strength of the granite specimen. Generally, when $\alpha$ or $\beta$ is a fixed value, the uniaxial 
compressive strength firstly decreases and then increases with the increase of $\beta$ or $\alpha$. At the same time, when $\alpha$ is $60^{\circ}$ and $\beta>45^{\circ}$, the uniaxial compressive strength represents a decreasing trend. And, the uniaxial compressive strength at $\alpha$ and $\beta$ between $30^{\circ}$ and $60^{\circ}$ is generally small.

(2) The failure pattern of the granite specimen depends on the included angles of $\alpha$ and $\beta$. When $\alpha$ is $30^{\circ}$ or $45^{\circ}$, no matter what the value of $\beta$ is, the main joint controls the crack propagation and failure of the granite specimen. The granite specimen mainly occurs the shear failure propagating from the main joint tips. At the same time, the secondary joint is the key joint for crack propagation and failure of the granite specimen at $\alpha$ of $0^{\circ}$ and $90^{\circ}$ except when $\beta$ is $90^{\circ}$. The granite specimen is mainly destroyed by the shear failure propagating from secondary joint tips. And, the shear failure crossing upper tips of the main and secondary joints is found in the granite specimen at $\alpha$ of $0^{\circ}$ or $90^{\circ}$ and $\beta$ of $90^{\circ}$. Also, the combined actions of the main and secondary joints determine the crack propagation and failure of the granite specimen at $\alpha$ of $60^{\circ}$ except when $\beta$ is $90^{\circ}$. The granite specimen failure is the hybrid failure pattern, including the shear failure propagating from the main joint tips and tensile failure propagating from the joint center or secondary joint tips. And, when $\alpha$ is $60^{\circ}$ and $\beta$ is $90^{\circ}$, the granite specimen occurs the shear failure along the secondary joint plane direction.

(3) There are three types of mesodisplacement field distributions for macrotensile crack. Firstly, the particles move in the same direction, and then parts of them change the movement direction or, they move apart. The third one is that particles move in opposite directions for microcrack generation. Moreover, particles located on both sides of macroshear crack move in the parallel and opposite directions.

\section{Conflicts of Interest}

The authors declare that they have no conflicts of interest.

\section{Acknowledgments}

This study was supported by National Natural Science Foundation of China (51474134, 51774194), Shandong Provincial Natural Science Foundation for Distinguished Young Scholars (JQ201612), Taishan Scholar Talent Team Support Plan for Advantaged \& Unique Discipline Areas, and Graduate Student Science and Technology Innovation Project of Shandong University of Science and Technology (SDKDYC180201).

\section{References}

[1] S. Y. Wang, S. W. Sloan, D. C. Sheng, S. Q. Yang, and C. A. Tang, "Numerical study of failure behaviour of precracked rock specimens under conventional triaxial compression," International Journal of Solids and Structures, vol. 51, no. 5, pp. 1132-1148, 2014.

[2] T. Wang, W. B. Zhou, J. H. Chen, X. Xiao, Y. Li, and X. Y. Zhao, "Simulation of hydraulic fracturing using particle flow method and application in a coal mine," International Journal of Coal Geology, vol. 121, pp. 1-13, 2014.

[3] S. R. Wang, H. G. Xiao, P. Hagan, and Z. S. Zou, "Mechanical behavior of fully-grouted bolt in jointed rocks subjected to double shear tests," DYNA, vol. 92, no. 3, pp. 314-320, 2017.

[4] H. Z. Li, C. C. Xia, X. D. Wang, J. F. Zhou, and C. S. Zhang, "Experimental study on deformation and strength properties of jointed marble specimens," Chinese Journal of Rock Mechanics and Engineering, vol. 27, no. 10, pp. 2118-2123, 2008.

[5] H. Niandou, J. F. Shao, J. P. Henry, and D. Fourmaintraux, "Laboratory investigation of the mechanical behavior of Tournemire shale," International Journal of Rock Mechanics and Mining Sciences, vol. 34, no. 1, pp. 3-16, 1997.

[6] H. J. Mao and C. H. Yang, "Study on effect of discontinuities on mechanical characters of slate," Chinese Journal of Rock Mechanics and Engineering, vol. 24, no. 20, pp. 3651-3656, 2005.

[7] M. Prudencio and M. V. S. Jan, "Strength and failure modes of rock mass models with non-persistent joints," International Journal of Rock Mechanics and Mining Sciences, vol. 44, no. 6, pp. 890-902, 2007.

[8] X. Chen, Z. H. Liao, and D. J. Li, "Experimental study of effects of joint inclination angle and connectivity rate on strength and deformation properties of rock masses under uniaxial compression," Chinese Journal of Rock Mechanics and Engineering, vol. 30, no. 4, pp. 781-789, 2011.

[9] C. Gehle and H. K. Kutter, "Breakage and shear behaviour of intermittent rock joints," International Journal of Rock Mechanics and Mining Sciences, vol. 40, no. 5, pp. 687-700, 2003.

[10] W. M. Xiao, R. G. Deng, X. M. Fu, and C. Y. Wang, "Model experiments on deformation and strength anisotropy of columnar jointed rock masses under uniaxial compression," Chinese Journal of Rock Mechanics and Engineering, vol. 33, no. 5, pp. 957-963, 2014.

[11] M. Goldstein, B. Goosev, N. Pvrogovsky, R. Tulinov, and A. Turovskaya, "Investigation of mechanical properties of cracked rock," Surface Review and Letters, vol. 7, no. 7, pp. 667-671, 1966.

[12] G. Reik and M. Zacas, "Strength and deformation characteristics of jointed media in true triaxial compression," International Journal of Rock Mechanics and Mining Sciences, vol. 15, no. 6, pp. 295-303, 1978.

[13] E. Z. Laijtai, "Strength of discontinuous rocks in direct shear," Géotechnique, vol. 19, no. 2, pp. 218-233, 1969.

[14] Y. Zhou, S. C. Wu, Y. T. Gao, and A. Misra, "Macro and meso analysis of jointed rock mass triaxial compression test by using equivalent rock mass (ERM) technique," Journal of Central South University, vol. 21, no. 3, pp. 1125-1135, 2014.

[15] X. B. Wang, "Effect of joint inclination on deformation and failure of rock specimen with a single joint in plane strain compression," Journal of Sichuan University, vol. 38, no. 2, pp. 24-29, 2006.

[16] S. Q. Yang and Y. H. Huang, "Particle flow study on strength and meso-mechanism of Brazilian splitting test for jointed rock mass," Acta Mechanica Sinica, vol. 30, no. 4, pp. 547-558, 2014.

[17] L. Yang, Y. Jiang, S. Li, and B. Li, "Experimental and numerical research on $3 \mathrm{D}$ crack growth in rocklike material subjected to uniaxial tension," Journal of Geotechnical and Geoenvironmental Engineering, vol. 139, no. 10, pp. 1781-1788, 2013. 
[18] S. P. Morgan, C. A. Johnson, and H. H. Einstein, "Cracking processes in Barre granite: fracture process zones and crack coalescence," International Journal of Fracture, vol. 180, no. 2, pp. 177-204, 2013.

[19] D. W. Yin, S. J. Chen, X. Q. Liu, and H. F. Ma, "Effect of joint angle in coal on failure mechanical behavior of roof rock-coal combined body," Quarterly Journal of Engineering Geology and Hydrogeology, 2017.

[20] P. Kulatilake, B. Malama, and J. Wang, "Physical and particle flow modeling of jointed rock block behavior under uniaxial loading," International Journal of Rock Mechanics and Mining Sciences, vol. 38, no. 5, pp. 641-657, 2001.

[21] Y. H. Huang and S. Q. Yang, "Discrete element study on strength and failure behavior of jointed sandstone with two sets of cross-joints," Journal of China Coal Society, vol. 40, no. 1, pp. 76-84, 2015.

[22] P. A. Cundall and O. D. Strack, "A discrete numerical model for granular assemblies," Géotechnique, vol. 29, no. 1, pp. 47-65, 1979.

[23] T. B. Zhao, W. Y. Guo, C. P. Lu, and G. M. Zhao, "Failure characteristics of combined coal-rock with different interfacial angles," Geomechanics and Engineering, vol. 11, no. 3, pp. 345-359, 2016.

[24] G. Wang, M. M. Wu, R. Wang, H. Xu, and X. Song, "Height of the mining-induced fractured zone above a coal face," Engineering Geology, vol. 216, pp. 140-152, 2017.

[25] J. F. Hazzard, R. P. Young, and S. C. Maxwell, "Micromechanical modeling of cracking and failure in brittle rocks," Journal of Geophysical Research, vol. 105, no. 7, pp. 16683-16697, 2000.

[26] A. Manouchehrian, M. Sharifzadeh, M. F. Marji, and J. Gholamnejad, "A bonded particle model for analysis of the flaw orientation effect on crack propagation mechanism in brittle materials under compression," Archives of Civil and Mechanical Engineering, vol. 14, no. 1, pp. 40-52, 2014.

[27] H. Lee and S. Jeon, “An experimental and numerical study of fracture coalescence in pre-cracked specimens under uniaxial compression," International Journal of Solids and Structures, vol. 48, no. 6, pp. 979-999, 2011.

[28] Z. Z. Liang, H. Xing, S. Y. Wang, D. J. Williams, and C. A. Tang, "A three-dimensional numerical investigation of the fracture of rock specimens containing a pre-existing surface flaw," Computers and Geotechnics, vol. 45, pp. 1933, 2012.

[29] Z. J. Wen, X. Wang, Q. H. Li, G. Lin, S. J. Chen, and Y. J. Jiang, "Simulation analysis on the strength and acoustic emission characteristics of jointed rock mass," Technical Gazette, vol. 23, no. 5, pp. 1277-1284, 2016.

[30] X. Wang, Z. J. Wen, and Y. J. Jiang, "Time-space effect of stress field and damage evolution law of compressed coal-rock," Geotechnical and Geological Engineering, vol. 34, no. 6, pp. 1933-1940, 2016.

[31] X. P. Zhang, G. Wang, Y. J. Jiang, and N. Huang, "Simulation research on granite compression test based on particle discrete element model," Rock and Soil Mechanics, vol. 35, no. 1, pp. 99-105, 2014.

[32] G. Wang, X. P. Zhang, Y. J. Jiang, B. Li, X. Z. Wu, and N. Huang, "Meso-mechanism research on shear failure of rock joint based on particle discrete element method," Journal of Central South University, vol. 46, no. 4, pp. 1442-143, 2015.

[33] Itasca Consulting Group, PFC2D (Particle Flow Code in 2 Dimensions) Fish in PFC2D, Itasca Consulting Group, Minneapolis, MN, USA, 2008.
[34] N. Cho, C. D. Martin, and D. C. Sego, "A clumped particle model for rock," International Journal of Rock Mechanics and Mining Sciences, vol. 44, no. 7, pp. 997-1010, 2007.

[35] P. F. Yin, "Experiment and particle flow simulation on mechanical properties of layered composite rock under uniaxial compression," M.Sc. thesis, China University of Mining Technology, Xuzhou, China, 2016.

[36] X. P. Zhang and L. N. Y. Wong, "Cracking processes in rocklike material containing a single flaw under uniaxial compression: a numerical study based on parallel bonded-particle model approach," Rock Mechanics and Rock Engineering, vol. 45, no. 5, pp. 711-737, 2012. 


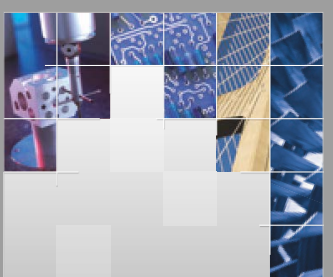

\section{Enfincering}
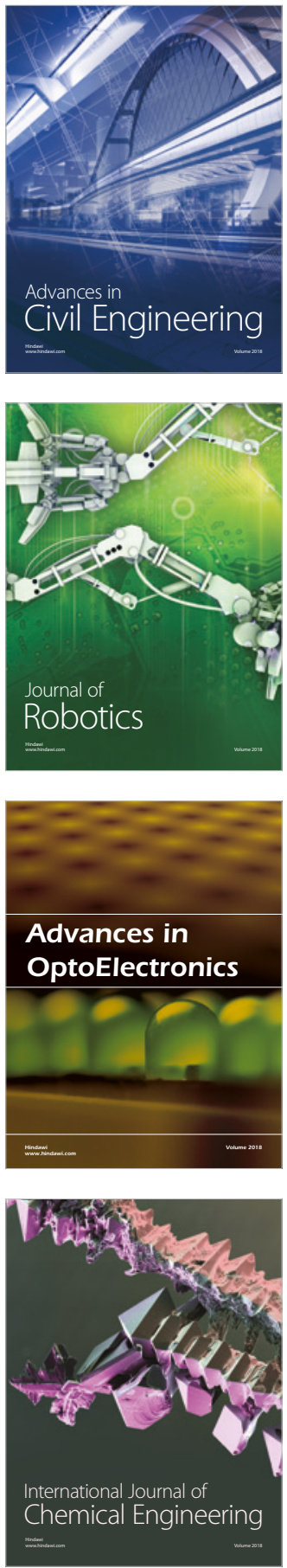

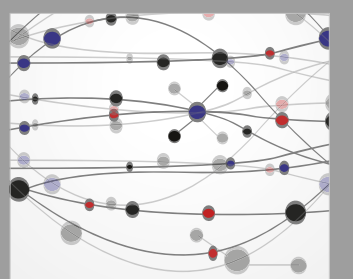

\section{Rotating \\ Machinery}

The Scientific World Journal

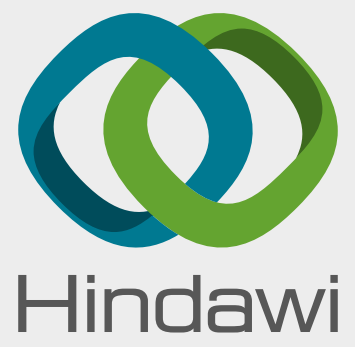

Submit your manuscripts at

www.hindawi.com
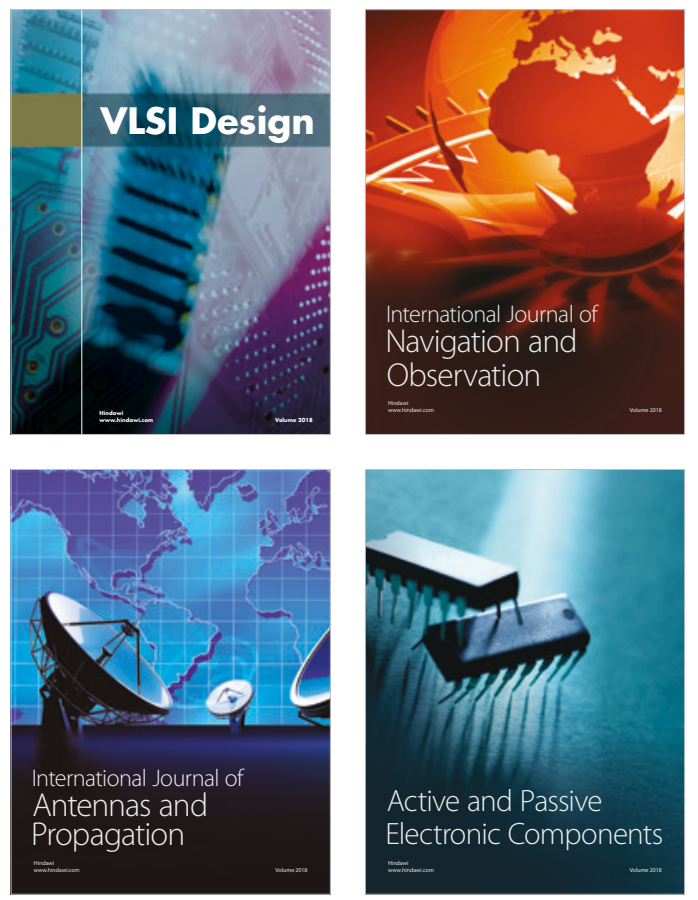
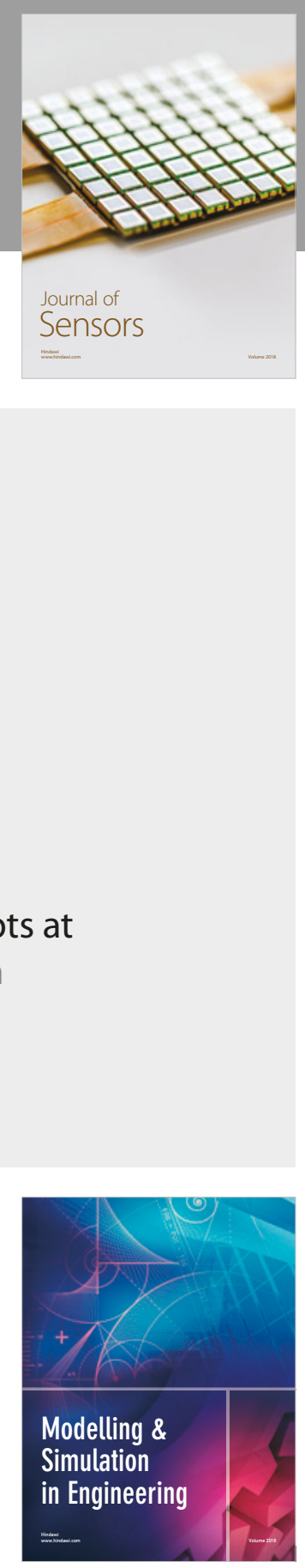

\section{Advances \\ Multimedia}
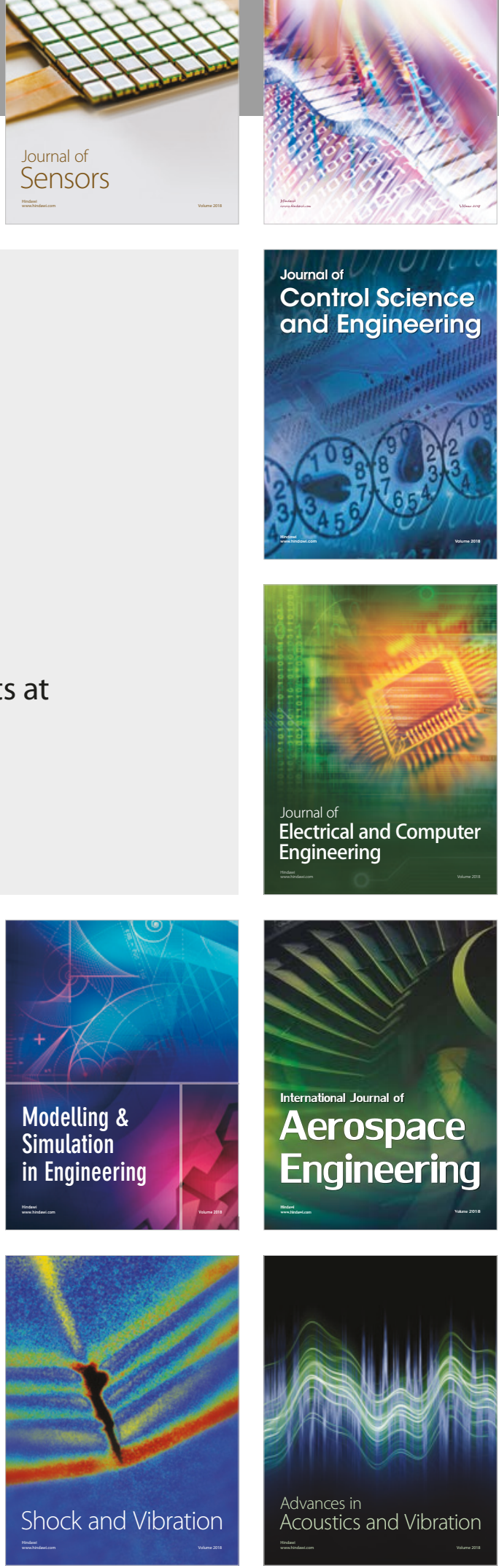